\title{
Assessing the efficiency and the criticality of the elements belonging to a complex territorial system subject to natural hazards
}

\author{
R. Minciardi ${ }^{1,2}$, R. Sacile ${ }^{1,2}$, and E. Trasforini ${ }^{2,3}$ \\ ${ }^{1}$ DIST - Department of Communication, Computer and System Sciences, University of Genova, Italy \\ ${ }^{2}$ CIMA - Centro di ricerca Interuniversitario in Monitoraggio Ambientale, Savona, Italy \\ ${ }^{3}$ DIFA - Dipartimento di Ingegneria e Fisica dell'Ambiente - University of Basilicata, Potenza, Italy
}

Received: 1 August 2005 - Revised: 14 October 2005 - Accepted: 14 October 2005 - Published: 2 January 2006

\begin{abstract}
The effects of natural hazards can be mitigated by the use of proper "pre-event" interventions on "key" elements of the territory, that is on elements that are mostly vulnerable to a given catastrophic scenario and whose loss of functionality can cause damages on people, property and environment. In this respect, methodologies and tools should be studied to support decision makers in the analysis of a territory, in order to point out such elements. In this work, vulnerability is taken into account under two aspects: "physical vulnerability", which measures the propensity of a territorial element to suffer damage when subject to an external stress corresponding to the occurrence of a natural phenomenon; "functional vulnerability", which measures the propensity of a territorial element to suffer loss in functionality, even when that is caused by the loss of functionality of other territorial elements. In the proposed modeling approach, vulnerability is represented through the use of a graph-based formalization. A territorial system is represented as a complex set of elements or sub-systems. Such elements have differentiated and dedicated functions, and they may be functionally interconnected among them. In addition, vulnerability is defined through the use of two different variables, namely the criticality and the efficiency. Focusing the attention on the temporal phases corresponding to the occurrence of a calamitous event, the first one measures the service demand of an element, whereas the efficiency is a measure of the service that can be offered by such an element. The approach presented is largely independent from the natural risk considered. Besides, the tools introduced for the vulnerability analysis of the territorial system can also be used to formalize decision problems relevant to the location of the available resources for emergency management. A specific case study pertaining to the hydrological risk in the Val di Vara area (Italy) is presented.
\end{abstract}

Correspondence to: E. Trasforini

(eva@cima.unige.it)

\section{Introduction}

It is generally reckoned that prevention activities play a fundamental role to mitigate the damages due to environmental catastrophes. Prevention activities on a territory are mostly devoted to the reduction of the vulnerability. In this respect, the terms "hazard" (that is related to the probability of occurrence of an extreme event with an estimated - low - frequency) and "risk" (that associates the occurrence probability of the extreme event with the losses it would imply) are world wide used with a common meaning. On the counterpart, there is much more uncertainty about the significance of the term "vulnerability" (Bogardi, 2004), and the research community still lacks a common conceptualization of vulnerability (Cutter, 1996). In general, it is felt that the concept of vulnerability, as related to a community living in a territory, is connected to its exposure and proximity to external events (susceptibility) and to its predisposition to suffer losses when exposed to natural or socially induced physical events (Lavell, 2000). From an engineering perspective and with reference to natural hazards, hazard reduction activities are usually based on studies involving the territorial system as a whole (for example, in the case of flood risk, example of such activities might be the construction of protective barriers, the adoption of certain policies in land use management, such as reforestation, etc.). On the other hand, vulnerability reduction activities are generally more devoted to the identification of infrastructures and building elements whose structure enhancement (for example by retrofitting) might effectively improve the functionality of the element itself even when exposed to a catastrophic scenario.

Actually, the quantification of the loss of functionality of a territorial element is a crucial problem, since it depends not only on its own characteristics (such as, for example, its integrity after the occurrence of a disastrous event), but also on the functionality of other elements, whose state may condition the functionality of the considered element. For example, in a certain territory, the impossibility to use a road, due 
to a landslide, can affect the functionality of several other territorial elements, whose functionality depends on the accessibility of that road.

The literature concerning risk assessment, for the various kinds of natural hazards, is quite copious. For example, as regards hydrologic risk one can refer to Siccardi et al. (2005), Horritt et al. (2002), and Krzysztofowicz (2001), for landslides hazard assessment one can refer to Varnes (1984), whereas for forest fire risk to Wybo et al. (1995), and Fiorucci et al. (2005), for industrial risk to Balducelli et al. (2000), and for transportation risk to Fabiano et al. (2002), and Giglio et al. (2004).

In any case, the general goal of a risk assessment procedure is to map the hazard over the considered territorial system, and to identify the territorial elements that are exposed to such a hazard, possibly evaluating the expected loss, for each element, due to the occurrence of an event compatible with the considered hazard distribution.

However, as already pointed out, the analysis of what may happen to any single element may not be sufficient to evaluate the potential impact of a given event over the whole considered territorial system. In fact, as above mentioned, the functionality of a territorial element (i.e., the capability to provide service or to ensure safety to the inhabitants, during an emergency phase) may be heavily affected by the mutual functional interconnections among the elements in the considered territory.

Thus, there is the necessity of developing a comprehensive approach that allows the analysis of the impact of a potential extreme event over a certain territorial system, taking into account both the direct and indirect effects of the event. A first attempt in this direction has been made in Minciardi et al. (2005). In this paper, that approach is extended and made deeper, in order to make it more suitable for application.

Moreover, in this paper, the use of such an approach is considered as regards the development of a decision support system (DSS) assisting decision makers, not only in the analysis of the impact, over a complex territorial system, of a certain disastrous event, but also in devising suitable strategies in order to mitigate such an impact.

The territorial system is modeled as a directed graph, in which nodes represent territorial elements worth to be individually considered, whereas links represent conditioning relationships between such elements. A key concept in evaluating the impact of an event over the considered territory is that of "functional integrity", or, more simply, "functionality". By such a term, the capability of a territorial element of providing service or safety conditions to the interested population is generically intended. In the following, more formal definitions will be provided.

In the next section, the formal representation of a territorial system will be introduced and a procedure for the vulnerability analysis will be discussed. Further, in Sect. 3, a procedure is presented to formulate a decision (optimization) problem concerning the mitigation of the vulnerability of the territorial system for a given scenario. Then, in Sect. 4, a case study is considered, and some final conclusions are drawn in Sect. 5.

\section{Vulnerability analysis of the territorial system}

As for other complex systems, a territorial system can be defined as the collection of elements characterized by individual features, interconnected by mutual causal relationships in such a way that the dynamic behavior of the state variables characterizing each element of the set has to be jointly determined.

In the case of a territorial system, the choice of the elements to be taken into account is largely dependent on the kind of hazard considered. The elements worth to be taken into account may be modeled either as points (e.g., buildings, industrial settlements, etc.), lines (e.g., roads, or other transport infrastructures), or areas (e.g. municipalities, regions, territory at risk). In some cases, it is convenient to consider explicitly a territorial element as made of several interconnected sub-elements.

Considering a specific hazard (hydrogeological, seismic, wildfire, etc.), the elements to be represented are those that are presumably involved in a given plausible scenario, both as possible sources of demand for intervention, and as structures capable of providing services within an emergency phase. It is clear that, as the territorial system is made of interconnected elements, damage to one of such elements may induce a loss in "functionality" for other elements that are not directly (i.e., physically) involved in the considered event.

An intuitive and effective way to represent the mutual conditioning relationships among the various territorial elements is that related to the use of influence diagrams (Howard et al., 1984; Schachter, 1988; Shenoy, 1992). These diagrams can be used to formalize explicitly the dependences among either stochastic or deterministic variables describing the state of the system. Such dependencies can be quantitatively evaluated on the basis of the know-how of experts, and of statistic information. The nodes in the influence diagram represent the variables in the system to be modeled, and the directed links identify conditional influences among them. A variable $x$ is said to influence a state variable $y$ (and then a directed link from $x$ to $y$ exists in the influence diagram) if information given about $x$ tells something about $y$.

The modeling approach proposed in this paper (that is an evolution of the methodology introduced by Minciardi et al., 2005) does not aim at representing a system with stochastic components. In addition, the nodes are not associated with variables, but with elements (or sub-elements) in the territory. For these reasons, in the following the term "graphs" will be used instead of "influence diagrams".

Then, let the territorial system be represented as a directed graph $G(E, F)$. Nodes belonging to set $E$ represent the territorial elements. Three sub-sets, in general not disjoint, of set $E$ can be identified:

- the sub-set $D$ of nodes representing elements that, when subject to an external stress, are affected by physical 
damages, thus requiring some service by other elements; such elements can be inadequate either to ensure satisfactory safety levels to people nearby, or to supply service to other elements belonging to the territorial system;

- the sub-set $R$ of nodes representing elements whose function is to provide the nodes belonging to sub-set $D$ with the required services; such nodes typically correspond to headquarters of policemen, firemen, civil protection, etc.;

- the sub-set $S$ of nodes representing infrastructure elements, which are necessary to allow elements of sub-set $R$ to provide the elements of sub-set $D$ with the required services.

A directed link $(i, j)$ is drawn between two nodes of set $E$, when the element associated to node $i$ conditions the functionality of the element corresponding to node $j$. Moreover, let $P(i)$ be the set of predecessors of node $i$, i.e., the set of nodes $j$ such that a directed link $(j, i)$ exists.

Then, let us consider a generic natural hazard of type $h$. Note that the graph representing the system, both for its topological aspects and the quantifications affecting its links (see below) is in general dependent on the particular kind of hazard considered. For this kind of hazard, one can suppose to consider a generic scenario, that is, a vector $\bar{\xi}=\operatorname{col}\left(\overline{\xi_{1}}, \overline{\xi_{2}}, \ldots, \overline{\xi_{N}}\right)^{T}$, being $N$ the number of the considered territorial elements, where $\bar{\xi}_{i}$ is the external stress vector (each component measures a specific physical quantity) that provides the intensity of the phenomenon, at the location corresponding to element $i$.

The formal representation of the territorial system requires the introduction of the following (numerical) indicators and functions for the elements within the considered territorial system:

$y_{i}$ physical integrity; this is a numerical indicator whose value belongs to interval $[0,1]$, where 1 corresponds to an element not affected by the external stresses corresponding to the considered scenario, and 0 corresponds to an element completely shattered by those stresses; owing to the definition of sub-set $D, y_{i}=1$ for all elements $i$ not belonging to $D$

$f_{i}\left(\bar{\xi}_{i}\right)$ physical vulnerability function of territorial element $i$; such a function represents the propensity of this element to suffer damage when subject to the external stresses corresponding to the occurrence of the considered scenario; it provides the value of the physical integrity, namely $y_{i}=f_{i}\left(\bar{\xi}_{i}\right)$; when the external stress can be described by a single scalar quantity $\xi_{i}$, the vulnerability function is represented by a non-increasing monotonic function with an asymptotic behavior, since the physical integrity of an element cannot drop below a certain value (that may coincide with zero);

$w_{i}$ functionality; such a value represents the functionality of each element when it is subject to the external stresses corresponding to the considered scenario; $f_{i}^{f}\left(y_{i} ; w_{k}, k \in P(i)\right)$ functional vulnerability function; such a function expresses the functionality $w_{i}$ of element $i$ as a function of the physical integrity of this element, and of the functionalities of the conditioning elements; note that the conditioning elements must belong to the set $R \cup S$.

Actually, the use of a generic term like "functionality" may be too vague, as each element (or, better, each homogeneous group of elements) is characterized by its own specific functionality, which is not easily comparable with the functionalities of other elements (or of other groups of elements). At the same time, a detailed study, involving each possible kind of functionality linked to the specific characteristics of the considered elements, could make unfeasible the resolution of the problem, as regards both the dimensions and the complexity of the vulnerability assessment model.

In the following, rather than generically referring to the functionality of an element, two different indicators will be used, depending on the sub-set the considered element belongs to:

$c_{i}$ criticality; this indicator is simply given by $1-w_{i}$, and is used only in connection with nodes belonging to sub-set $D$; it may assume values belonging to interval $[0,1]$, where 1 corresponds to an element whose functionality is completely zeroed, and 0 corresponds to an element whose functionality is not affected at all within the considered scenario;

$w_{i}$ efficiency; this indicator coincides with the functionality, and is used only in connection with elements belonging to sub-set $R \cup S$.

A possible structure for the functional vulnerability functions for the elements of the territorial system is

$w_{i}=y_{i} \cdot \prod_{k \in P(i)} Z_{i k}\left(w_{k}\right) \quad i \in R \cup S \cup D$,

where $Z_{i k}\left(w_{k}\right)$ is a function expressing the functional conditioning of element $k$ on element $i$ given by

$Z_{i k}\left(w_{k}\right)=\frac{1-\alpha_{i k}^{-1} e^{-\alpha_{i k} w_{k}^{2}}}{1-\alpha_{i k}^{-1} e^{-\alpha_{i k}}} \quad i \in R \cup S \cup D \quad k \in P(i)$,

where parameter $\alpha_{i k}$ is used to express the level of conditioning influence of element $k$ with respect to element $i$. A possible way to evaluate such a parameter is reported in the following. The value of parameter $\alpha_{i k}$ is generally related to the degree of sensitiveness of the functionality of element $i$ with respect to the functionality of element $k$. For instance, values $1,1.5,3$, and 6 of parameter $\alpha_{i k}$, may be used to indicate a strong influence, a medium-strong influence, a mediumweak influence and a weak influence, respectively. One can note that, in any case, the value of the function $Z_{i k}\left(w_{k}\right)$ is equal to 1 when the argument has value 1 . This is consistent with the meaning of this function, as no reduction in the functionality of element $i$ may be induced by element $k$, when this element is fully functional.

Then, in correspondence to a given scenario, the vulnerability analysis of a certain territorial system can be obtained by the following procedure: 
1. solve the system of nonlinear Eqs. (1), (2), written only for $i \in R \cup S$, thus obtaining the efficiency of each element $i \in R \cup S$; this step requires the solution of a system of non-linear equations, and then, in general, the use of an iterative numerical procedure;

2. compute directly by

$c_{i}=1-y_{i} \cdot \prod_{k \in P(i)} Z_{i k}\left(w_{k}\right) \quad i \in D$

the criticality of each element in $D$ (since the conditioning elements may belong only to sub-set $R \cup S$ ).

Possible ways can be devised to assess, in an objective way (i.e., on the basis only of quantitative information related to the territorial elements under concern), the values of the parameters appearing in functions (2). For instance, referring to the conditioning influence of a service center $p$ of category $j$ (e.g., such a category may include all civil protection centers and headquarters) over a urban settlement $r$, let us consider the following parameters (that could be easily found in a geo-referenced database):

$R_{j}$ sub-set of centers of category $j$;

$E_{p}$ number of employees of center $p$, of category $j$;

$I_{r}$ number of inhabitants of urban settlement $r$;

$d_{r p}$ distance between urban settlement $r$ and center $p$.

Then, a possible simple way to express the level of influence of element $p$ over element $r$ is that of introducing an un-normalized parameter $\tilde{\alpha}_{r p}$ defined as

$\tilde{\alpha}_{r p}=\frac{E_{p}}{I_{r}} \frac{1}{\sum_{q \in R_{j}} E_{q}} e^{-0.5 d_{r p}}$.

This parameter is generally not expressed within a scale suitable for the utilization in Eq. (2), and thus it has to be rescaled, obtaining parameter $\alpha_{r p}$ as follows

$\alpha_{r p}=a\left(1-\frac{\tilde{\alpha}_{r p}}{\max _{s \in U, q \in R_{j}}\left\{\tilde{\alpha}_{s q}\right\}}\right)$,

where $U$ is the set of urban elements over the considered territory, and $a$ is a scale factor. Expressions analogous to Eqs. (4) and (5) can be introduced for all the categories of elements that have to be taken into account in the vulnerability analysis of the territorial system.

\section{An optimal resource location problem}

The results of the systemic vulnerability analysis can be obviously used in order to deepen the knowledge of the territory under consideration, and its response to a certain considered scenario. The criticality values can be used in order to identify the elements that would be most heavily affected by the phenomena occurring in the considered scenario, and thus primarily require to devise suitable interventions to mitigate hazard exposure, or to reduce the effects of the conditioning by other elements. On the other side, the efficiency values allow to evaluate the effectiveness of the elements involved (either actively or passively) in the emergency management phase.

A further application of the models and the concepts introduced in the previous section is related to the possibility of formalizing optimal (preventive) resource location problems, as regards emergency management. Namely, mathematical programming problems may be defined, having the objective of distributing the (scarce) resources over the considered territory, in order to protect such elements that, in connection with a catastrophic natural event, may be characterized by the highest criticality.

More specifically, given a set of available resources (for the sake of simplicity, just one kind of resources is considered), the optimal location (assignment) of such resources to the various service centers is considered within a completely deterministic setting. The decision variables representing the amount of resources assigned to the various service centers are assumed to be continuous variables (i.e., the available amount of resources is considered as continuously divisible). This assumption is not completely acceptable whenever (as it happens in most cases) the resources (e.g., men, means) are discrete in nature. However, as the number of the available resources is generally high, even in this case the (integer) decision variables may be viewed as real ones in the formalization of the optimization problems.

For the statement of the optimal resource location problem, the following definitions are necessary, in addition to those provided in the previous section:

$x_{i}$ decisional continuous variable providing the number of resources that are assigned to node $i$ belonging to sub-set $R$; $X$ total amount of available resources;

$e_{i j}$ contribution of the efficiency of element $j$ to the correct functioning of element $i$. It corresponds to the value assumed by function $Z_{i j}\left(w_{j}\right)$ in connection with the specific scenario; $e_{i j}$ assumes values in the continuous interval $[0,1]$, where 1 indicates that the efficiency of $j$ is not reduced because of $i$, whereas 0 indicates that the reduced efficiency of $j$ is making pointless the role of center $i$;

$p_{l}$ potential service demand associated to the generic node $l$ belonging to sub-set $D$; it represents a measure of the necessary interventions (e.g., the number of persons requiring transportation to a medical center).

Then, the following decision problem can be formalized, as regards the assignment of the resources to the location centers (e.g., headquarters), in order to minimize the maximum criticality over the considered area. The objective of the problem is to assign resources to centers in order to mitigate the effects of the occurrence of a catastrophic event over the whole area. In particular, the objective (to be minimized) is the maximum criticality, over all elements in $D$, in connection with the considered scenario, and under the selected values of the resource location variables, $x_{i}, \mathrm{i} \in R$.

The optimization problem is

$\min Z=\max _{i \in D}\left\{c_{i}\right\}$ 
s.t. the following constraints

$$
\begin{aligned}
& c_{i}=1-y_{i} \cdot \prod_{k \in P(i)} e_{i k} \quad i \in D \\
& w_{i}=y_{i} \cdot \prod_{k \in P(i)} e_{i k} \quad i \in R \cup S \\
& e_{i j}=\frac{1-\alpha_{i j}^{-1} e^{-\alpha_{i j} w_{j}^{2}}}{1-\alpha_{i j}^{-1} e^{-\alpha_{i j}}} \quad i \in D \cup R \cup S \quad j \in P(i) \\
& \tilde{\alpha}_{i j}=\frac{x_{j}}{p_{i}} \frac{1}{X} e^{-0.5 d_{i j}} \quad i \in D \quad j \in R, j \in P(i)
\end{aligned}
$$

$$
\alpha_{i j=a}\left(1-\frac{\tilde{\alpha}_{i j}}{\max _{\substack{s \in D \\ q \in R \\ q \in P(s)}}\left\{\tilde{\alpha}_{s q}\right\}}\right) \quad i \in D \quad j \in R, j \in P(i)
$$

$\sum_{j \in R} x_{j}=X$

$x_{j} \geq 0 \quad j \in R$

In the above problem statement, constraints (7) and (8) represent the expressions of the criticality and the efficiency of the various elements. Constraints (9), (10) and (11) are analogous to (2), (4), (5). Note that constraints (10) are written in order to express the influence of the resource assignments to location centers over elements of the sub-set $D$. Note that in the statement of the problem only the $\tilde{\alpha}_{i j}$ (and the $\alpha_{i j}$ ) such that $i \in D, j \in R, j \in P(i)$ have to be considered as decision variables, whereas the other ones (referring to other conditioning influences) are considered as fixed, as they are not affected by the considered resource location problem. The physical integrities $y_{i}$, for each element belonging to $D$, are retained as given quantities, in the considered scenario. Constraints (11) are necessary for parameter scaling. Finally, constraint (12) specifies the amount of resources globally assignable.

It is worth noting that the above problem is just one among the various possible problems that could be stated in connection with the above considered resource assignment framework. For instance, one could consider, instead of the objective function in Eq. (6), another objective function expressing the sum of the criticalities, for the various elements in $D$. The meaning of the choice of this objective function is apparent: instead of trying to reduce, as far as possible, the criticality of the less favored element, this choice would attempt to reduce the average criticality. Depending on the particular context, the former or the latter choice (or even another one) may be suitable.

It must be remarked that the optimization problem above formulated is referred just to a given scenario (and to a given type of hazard). On the other hand, the definition of the location of resources at the various service centers should take into account a multiplicity of scenarios. Such scenarios should be considered along with their probabilities of occurrence, and possibly they could refer to different kinds of natural hazards. However, the formulation of the optimal location of resources taking into account a multiplicity of scenarios (each weighted by its probability of occurrence) can be viewed as a generalization of the kind of problems introduced in this section, and thus, for the sake of brevity, it is omitted

\section{Application to a case study}

The proposed approach has been applied to a case study relevant to the hydrologic risk in the Vara catchment in Liguria region, Italy. More precisely, some results are presented, relevant to the application of the procedure for the analysis of the systemic vulnerability in the Vara catchment area.

First, an analysis and a characterization of the territorial elements in the Vara catchment relevant to the emergencies that can arise from probable hydrologic hazardous events have been performed. Then, the functional relationships among these elements have been identified and quantitatively evaluated.

Further, some significant hydrologic scenarios have been selected, and the elements that might be directly involved in such events have been identified. Finally, the vulnerability analysis of the whole territorial system has been carried out, following the procedure described in Sect. 2. In the following, the sequence of such phases is described in detail.

\subsection{Description of the territorial model relevant to the Vara catchment}

The Vara River is an affluent of the Magra River, one of the seven catchments of inter-regional interest in Italy. The Vara catchment lies in Liguria region, near the northwestern coast of Italy, and it covers a territory of roughly $560 \mathrm{~km}^{2}$, for a river length of about $60 \mathrm{~km}$ (see Fig. 1). The territory belonging to the Vara catchment is mainly mountainous, and it is characterized by small and scattered urban centers, concentrated in the downstream area of the basin. The overall population is about 30000 inhabitants, without any significant periodicity dependent on the season of the year.

A detailed analysis of the territory has allowed the definition of the directed graph representing the territorial system of the Vara basin. The nodes of this graph are represented by the main urban settlements, the stretches of the road network, the medical centers, and the main operational centers (policemen, firemen,...) that play an active role in an emergency management phase.

Urban settlements have been only taken into account when directly affected by the phenomena characterizing the considered scenarios. Thus, as it is better explained in the following, just those elements that lie in the flood area relevant 


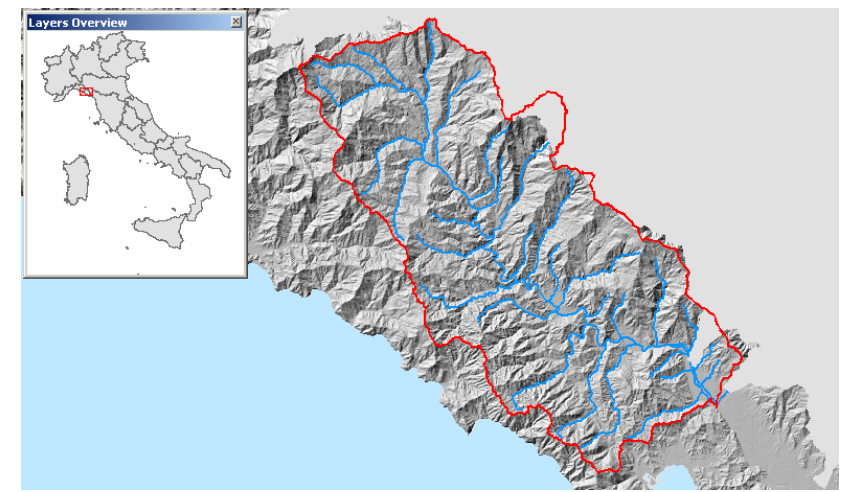

Fig. 1. The Vara basin and its localization within the Italian territory. The red line encompasses the basin, whereas the blue lines identify the basin hydrography.

to a return time $\mathrm{T}=30, \mathrm{~T}=200$, or $\mathrm{T}=500$ (Rosso and Kottegoda, 1997) have been considered.

A simplified road network has been used, composed of more than 80 elements. Such elements represent the main infrastructures, and the main links among the urban centers. Despite this simplification, in this way, it is possible to adequately characterize the road network.

As regards sub-set $R, 13$ operational units and 8 healthcare units have been identified and considered for the vulnerability analysis.

The information relevant to the localization (where available) of the considered territorial elements has been superimposed on the map of the flood areas, for the different return times, characterizing the river basin. In this context, two different scenarios have been considered, characterized by return times $\mathrm{T}=200$ and $\mathrm{T}=500$ years, respectively. In the first one, referred in the following as "Scenario A", 36 elements belong to sub-set $D$. In the other one, referred in the following as "Scenario B", 40 elements belong to sub-set $D$. Thus, the number of elements belonging to the sub-set $D$ of nodes directly involved in the scenario event is dependent on the return time one refers to. Moreover, no operational unit or health care unit belongs to sub-set $D$ (neither in Scenario A or in Scenario B).

Each element belonging to sub-set $D$ has been characterized in terms of its loss of physical integrity, on the basis of the information relevant to its inclusion, or not, into the different flood areas.

More precisely, in Scenario A, if an element is located just in the $\mathrm{T}=200$ flood area, it has been assumed that such an element is characterized by a physical integrity loss of $50 \%$. If such an element is also located in the $\mathrm{T}=30$ years flood area, a loss of physical integrity equal to $75 \%$ has been assigned to it.

Referring to Scenario B, if an element is only located in the $\mathrm{T}=500$ flood area, it has been assumed that such an element is characterized by a physical integrity loss of $50 \%$. If such an element was located both in the $\mathrm{T}=200$ and in the $\mathrm{T}=500$ years flood area, a loss of physical integrity equal to $75 \%$ has

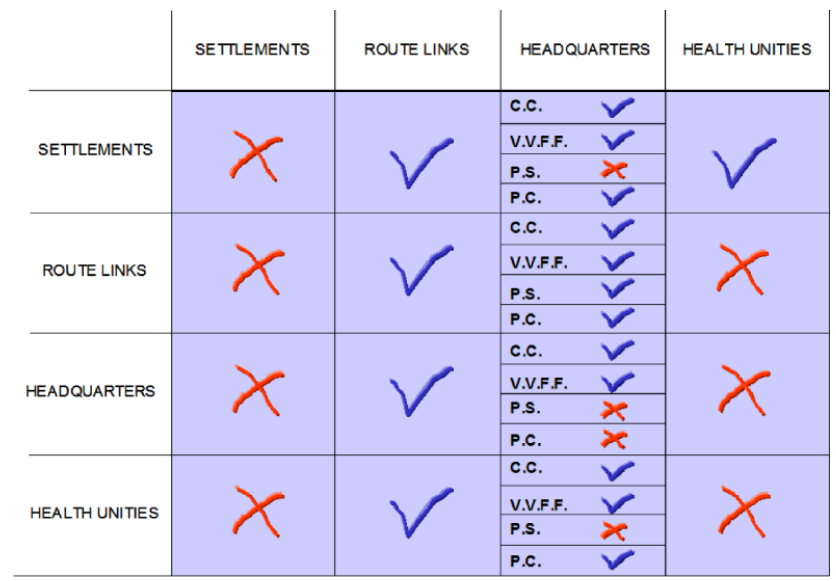

Fig. 2. Categories of nodes for which the influence evaluation has been performed. A blue "V" means that the category of nodes on the row has been considered as influenced by the category of nodes on the corresponding column, whereas a red " $\mathrm{X}$ " means that such an influence has not been taken into account.

been assigned to it. If, in addition, the element belonged to the $\mathrm{T}=30$ years flood area, it has been assumed that such an element is characterized by a physical integrity loss of $85 \%$.

Referring to the classification introduced in Sect. 2, it has been necessary to identify the elements belonging to the subsets $R$ and $S$. Sub-set $R$ is made by 21 headquarters, ambulatories and hospitals. Sub-set $S$ is made by 81 stretches of the simplified road network. The union of the three sub-sets $D, R$ and $S$ is composed of 112 elements within scenario B.

Once the determination of the elements involved in the analysis was carried out, the evaluation of the functional dependencies among the nodes has been performed. Such an evaluation has been only carried out for those couples of node typologies for which both a conditioning node and a conditioned node has been actually identified in the considered area. Figure 2 shows the influence evaluations that have been carried out: a blue "V" in the table means that the category of nodes on the row is influenced by the category of nodes on the column, whereas a red " $\mathrm{X}$ " means that such an influence does not exist.

The influences, evaluated through Eqs. (4) and (5), are associated to the links of the directed graph under consideration. The overall influence structure (i.e., for each node $i$, the predecessor nodes and the values of parameters $\alpha_{i j}$ ) is reported in Appendix A.

\subsection{Application of the proposed procedure}

The vulnerability analysis of the territorial system has been performed in connection with the two selected scenarios. In the following, the primes " $A$ " and " $B$ " are used in order to indicate parameters and variables referring to Scenarios A and $\mathrm{B}$, respectively.

The results that have been obtained by the application of the procedure proposed in Sect. 2, in order to characterize the elements belonging to sub-set $D$ in terms of criticality, and 


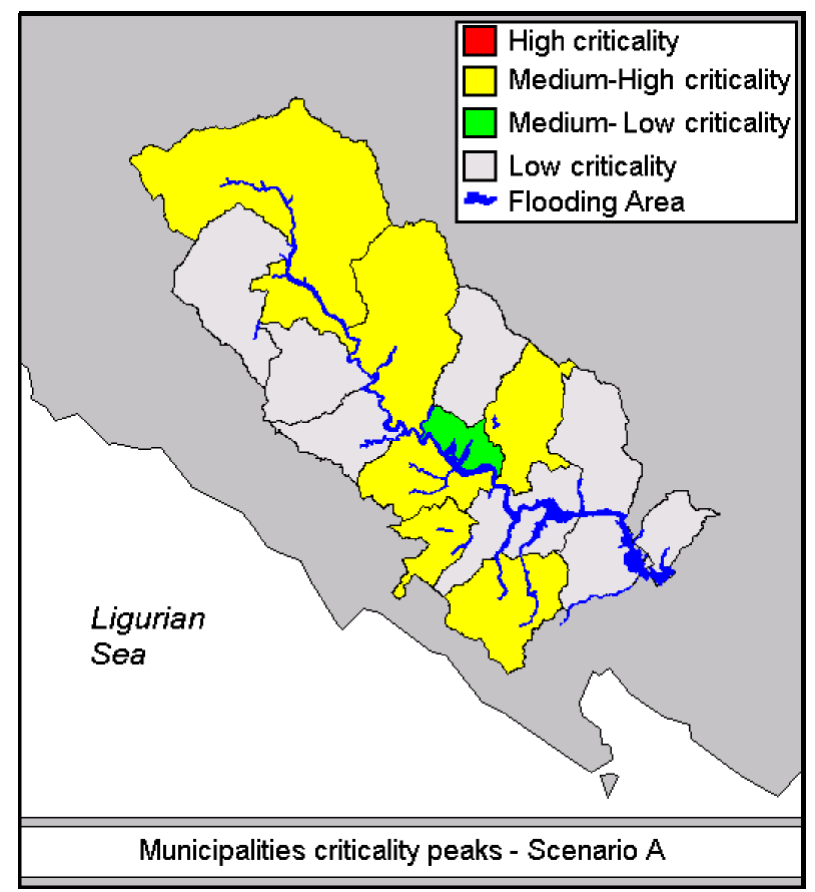

Fig. 3. The municipalities of the Vara basin have been characterized by the values of the most critical urban center belonging to such a municipality in Scenario A. The flood area relevant to this scenario (namely, the flood area characterized by $\mathrm{T}=200$ years) is represented in blue.

the elements belonging to the sub-sets $R$ and $S$ in terms of efficiency.

In Scenario A, 37 elements result to be characterized by a positive value of the quantity $c_{i}^{A}-\left(1-y_{i}^{A}\right)$ (namely, the criticality increase, i.e. the difference among the criticality and the complement to one of the physical integrity). Such an increase is due to an indirect effect induced by the conditioning influences of other considered elements. The mean value of the above quantities, over all such 37 elements, is equal to 0.02 ; the maximum value is equal to 0.19 (corresponding to a urban settlement belonging to the Municipality of Brugnato).

Then, as the overall criticality assessment is interesting for civil protection purposes, the most suitable administrative level appears to be the municipality one. For this reason, it seems reasonable to associate the highest value of criticality, among the territorial elements - mainly urban settlements belonging to its area, to each municipality, as shown in Fig. 3 for Scenario A.

On the other hand, referring to the efficiency, it has been noted that some elements are characterized by an efficiency decrease, which is due to the direct effects of the scenario phenomena. More specifically, 28 elements belonging to sub-set $S$ are characterized by such a decrease. The existence of functional dependences among the elements implies a further decrease in the efficiencies for some elements belonging to sub-sets $S$ and $R$. In fact, the mean value, over such elements, of the physical integrities (evaluated without taking into account the conditioning influences) is equal to

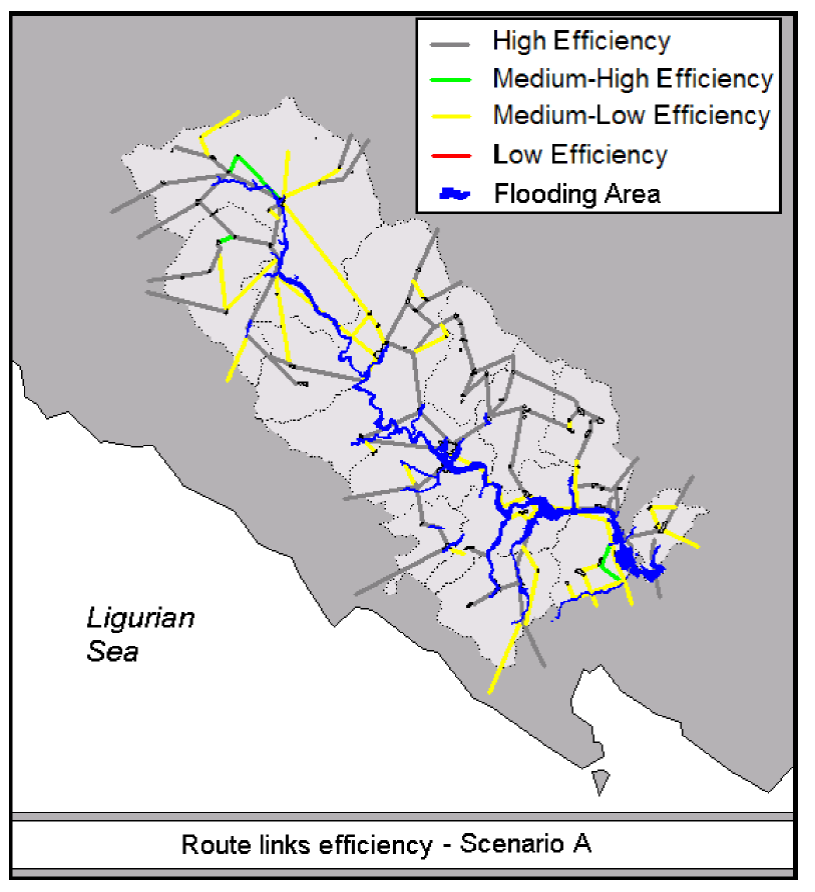

Fig. 4. Representation of the road network of the Vara basin, in which each road link is characterized on the basis of the efficiency obtained in connection to Scenario A. The flood area relevant to this scenario (namely, the flood area characterized by $\mathrm{T}=200$ years) is represented in blue.

0.80 , whereas the mean value over the same set of elements of the efficiency (evaluated taking into account such influences) is equal to 0.76. Actually, the elements that are characterized by the lowest values of efficiency could not correspond to those elements for which the decrease of efficiency (taking into account the conditioning influences by other elements) is highest. For instance, the lowest value of efficiency can be found in connection to a road link belonging to the municipality of Borghetto Vara (in the medium part of the valley, in the proximity of the flood area relevant to $T=200$ years), whereas the highest value of efficiency decrease can be found in connection to a road link in the municipality of Varese Ligure (in the upriver area, directly connected to another road heavily affected in the scenario event). Figure 4 represents the efficiencies corresponding to the road links in Scenario A, whereas Fig. 5 represents the efficiency decrease of the same elements, always in connection with Scenario A.

In Scenario B, 40 elements are characterized by a positive value of the criticality increase, with a mean criticality decrease among such elements equal to 0.10 . The maximum value of the difference $c_{i}^{B}-\left(1-y_{i}^{B}\right)$ is again related to the Municipality of Brugnato, but in this case such a value is equal to 0.48 . Here again, the maximum value of such a difference does not correspond to the maximum value of the criticality over the considered nodes, which can be found in connection to the Municipality of Varese Ligure (here, the criticality in Scenarios B is equal to 0.89). Finally, Fig. 6 shows the highest values of criticality characterizing each 


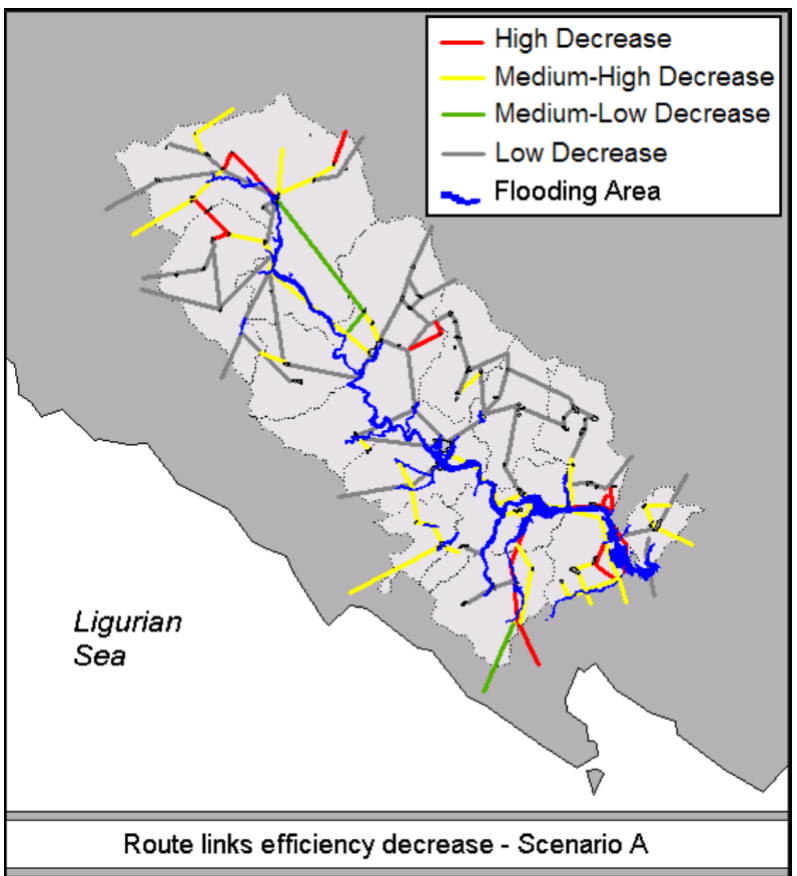

Fig. 5. Representation of the road network of the Vara basin, in which each road link is characterized on the basis of the difference between its physical integrity and the efficiency obtained in connection to Scenario A. The flood area relevant to this scenario (namely, the flood area characterized by $\mathrm{T}=200$ years) is represented in blue.

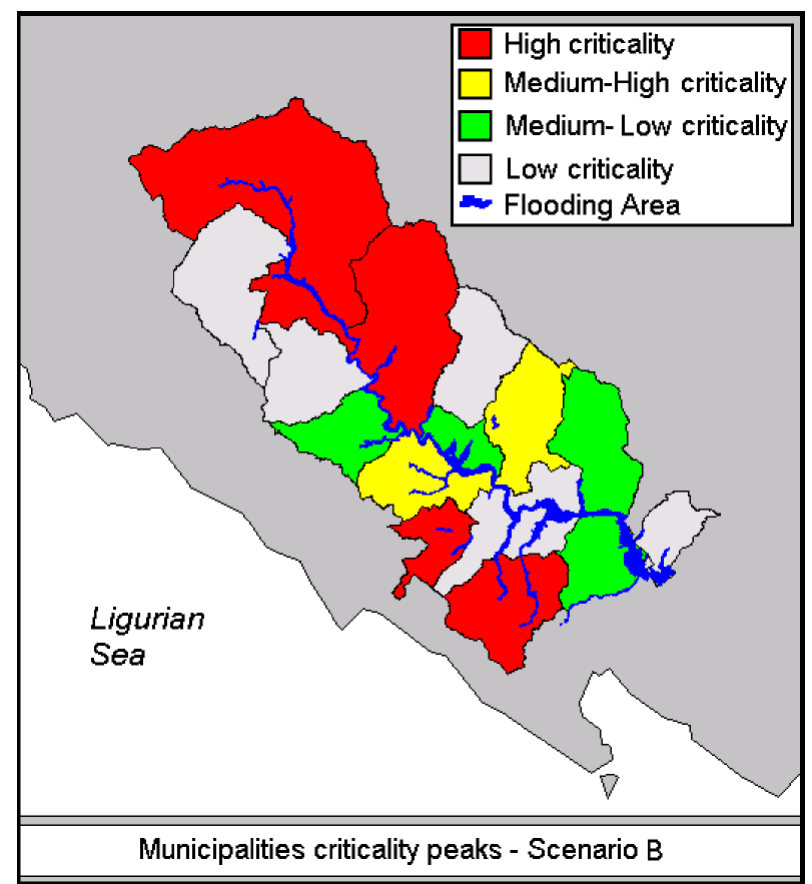

Fig. 6. The municipalities of the Vara basin have been characterized by the values of the most critical urban center belonging to such a municipality in Scenario B. The flood area relevant to this scenario (namely, the flood area characterized by $\mathrm{T}=500$ years) is represented in blue.

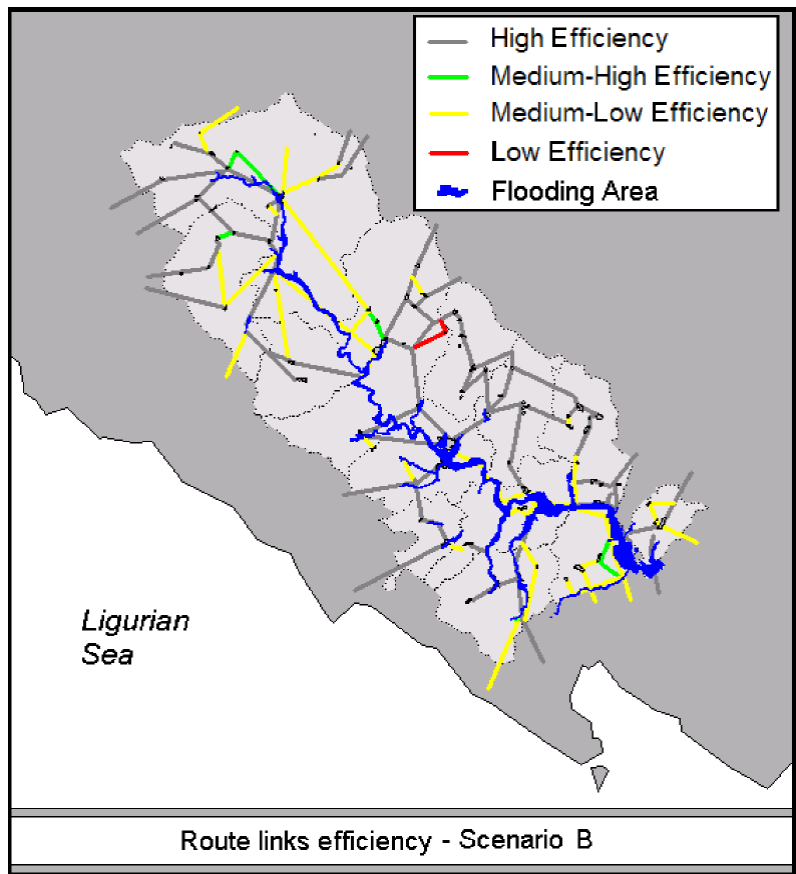

Fig. 7. Representation of the road network of the Vara basin, in which each road link is characterized on the basis of the efficiency obtained in connection to Scenario B. The flood area relevant to this scenario (namely, the flood area characterized by $\mathrm{T}=500$ years) is represented in blue.

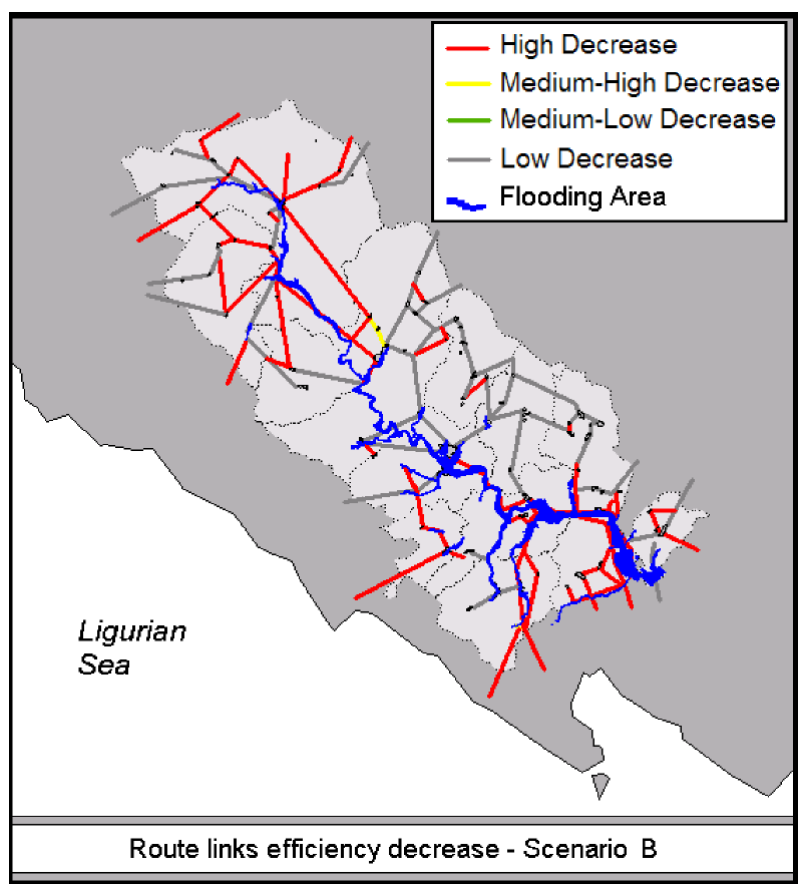

Fig. 8. Representation of the road network of the Vara basin, in which each road link is characterized on the basis of the difference between its physical integrity and the efficiency obtained in connection to Scenario B. The flood area relevant to this scenario (namely, the flood area characterized by $\mathrm{T}=500$ years) is represented in blue. 
municipality in Scenario B.

As in the previous scenario, 28 elements belonging to subset $R$ are directly involved in the event, but now the physical integrity values of such elements are lower, as well as the mean physical integrity value over all the elements belonging to sub-sets $R$ and $S$ (equal to 0.78 ). Also the mean efficiency value is lower than in Scenarios A, and it is equal to 0.73 . Here again, the elements that are characterized by the lowest efficiency and by the highest value of efficiency decrease do not coincide. Such evaluations are summarized by Figs. 7 and 8 , respectively.

A synthesis of the overall obtained results is reported in Appendix A.

\section{Conclusions and further research directions}

This paper introduces a formal approach, based on a previous technique presented in Minciardi et al. (2005), for the representation and the vulnerability analysis of a territorial system when subject to extreme natural events corresponding to given scenarios. The approach has been presented in order to stress its conceptual independence from the particular area considered, and, above all, from the kind of natural hazard. A case study has also been discussed relevant to hydrogeological hazard in a basin located in North Italy. Despite several simplifying assumptions regarding the resource characterization, the modeling of conditioning influences, and the representation of the territorial system, the paper provides a conceptual framework within which analysis and decision problems relevant to long-term planning can be posed.

Further research directions should regard essentially three issues. The first one is related to the complexity of the model. In fact, different categories of resources could be considered, and the ways to represent the conditioning influences among the various territorial elements should be refined and made more dependent (also in the structure) on the particular kind of the pair of elements. Second, as the problems addressed refer to long-term planning, the use of statistical information, and of a mathematical representation of the uncertainties related to risk assessment, would make the analysis procedures and the position of the resource location problems more sound. Finally, the management of an emergency (corresponding to a certain scenario, represented taking into account the dynamics of the event) should be viewed as a dynamic problem. In this respect, the criticalities and the efficiencies of the various elements should be evaluated as dynamically evolving during the various phases of the event and of the emergency management process.

\section{Appendix A}

Here the main characteristics of the case study are reported, in order to allow the reader to understand its structure and the complexity. Such elements are reported in Table A1.

More precisely, for each node $i$, the following information is reported:

- the category to which the elements belong, namely S (settlement), R (road links), or H (headquarter);

- the set of predecessor nodes $j$, characterized by the level of influence $\alpha_{i j}$;

- the level of physical integrity in the two different scenarios, namely $y_{i}^{A}$ and $y_{i}^{B}$;

- the criticality of the element (if it belongs to sub-set $D$ ) in the two Scenarios, namely $c_{i}^{A}$ and $c_{i}^{B}$;

- the efficiency of the element (if it belongs to sub-set $R$ or sub-set $S$ ) in the two Scenarios, namely $w_{i}^{A}$ and $w_{i}^{B}$. 
Table A1. For each considered element/node, the category, the set of predecessor nodes (characterized by the level of influence $\alpha_{i j}$ ), and the main results obtained in connection to Scenarios A and B are reported.

\begin{tabular}{|c|c|c|c|c|c|c|c|c|}
\hline Node $i$ & Node type & Predecessor node $j$ (along with value $\alpha_{i j}$ ) & $y_{i}^{A}$ & $y_{i}^{B}$ & $c_{i}^{A}$ & $c_{i}^{B}$ & $w_{i}^{A}$ & $w_{i}^{B}$ \\
\hline 1 & $S$ & $\begin{array}{l}28(1.5), 92(6.28), 93(6.95), 94(6.97), 95(7.72), 96(8.73), 97(9.03), 98(7.92), \\
100(7.92), 101(8.22), 102(8.79), 103(8.74), 104(9.28), 105(9.41), 109(1.5) \\
110(9.93), 111(10), 112(10)\end{array}$ & 1 & 0.9 & - & 0.17 & - & - \\
\hline 2 & $S$ & $\begin{array}{l}33(1.5), 92(9.95), 93(9.95), 94(9.96), 95(9.93), 96(9.97), 97(9.98), 98(9.95) \\
100(9.95), 101(9.96), 102(9.97), 103(9.97), 104(9.98), 105(9.95), 109(9.83) \\
110(10), 111(10), 112(10)\end{array}$ & 0.25 & 0.15 & 0.76 & 0.86 & - & - \\
\hline 3 & $S$ & $\begin{array}{l}25(1.5), 92(9.7), 93(9.7), 94(9.74), 95(9.66), 96(9.84), 97(9.88), 98(9.74), 100(9.74), 101(9.77) \\
102(9.83), 103(9.84), 104(9.91), 105(9.68), 109(8.54), 110(10), 111(10), 112(10)\end{array}$ & 0.25 & 0.15 & 0.76 & 0.86 & - & - \\
\hline 4 & $S$ & $\begin{array}{l}57(1.5), 92(9.86), 93(9.85), 94(9.88), 95(9.83), 96(9.89), 97(9.92), 98(9.83), 100(9.83), 101(9.85), \\
102(9.88), 103(9.9), 104(9.94), 105(9.82), 109(9.93), 110(10), 111(10), 112(10)\end{array}$ & 0.25 & 0.15 & 0.76 & 0.86 & - & - \\
\hline 5 & $S$ & $\begin{array}{l}26(1.5), 92(8.94), 93(8.97), 94(9.07), 95(9.36), 96(9.58), 97(9.68), 98(9.33), 100(9.33), 101(9.42), \\
102(9.61), 103(9.59), 104(9.76), 105(9.68), 109(9.35), 110(9.91), 111(10), 112(10)\end{array}$ & 1 & 0.9 & - & 0.17 & - & - \\
\hline 6 & $\mathrm{~S}$ & $\begin{array}{l}92(9.71), 93(9.61), 94(9.75), 95(9.76), 96(9.73), 97(9.79), 98(9.6), 100(9.6), 101(9.66), 102(9.77), \\
103(9.73), 104(9.85), 105(9.88), 109(9.99), 110(9.96), 111(10), 112(10)\end{array}$ & 0.75 & 0.65 & 0.5 & 0.36 & - & - \\
\hline 7 & $S$ & $\begin{array}{l}40(7.88), 42(7.88), 53(7.88), 54(7.88), 92(9.97), 93(9.96), 94(9.97), 95(9.97), 96(9.97), 97(9.97), 98(9.94) \\
100(9.94), 101(9.95), 102(9.97), 103(9.97), 104(9.98), 105(9.98), 109(10), 110(10), 111(10), 112(10)\end{array}$ & 0.75 & 0.5 & 0.44 & 0.73 & - & - \\
\hline 8 & $S$ & $\begin{array}{l}54(1.5), 92(9.9), 93(9.87), 94(9.91), 95(9.9), 96(9.9), 97(9.92), 98(9.84), 100(9.84), 101(9.86), 102(9.9), \\
103(9.9), 104(9.94), 105(9.91), 109(9.99), 110(10), 111(10), 112(10)\end{array}$ & 0.25 & 0.15 & 0.76 & 0.86 & - & - \\
\hline 9 & $\mathrm{~S}$ & $56(1.5)$ & 1 & 0.9 & - & 0.16 & - & - \\
\hline 10 & $\mathrm{~S}$ & $\begin{array}{l}59(7.17), 61(7.17), 62(7.17), 92(9.95), 93(9.94), 94(9.96), 95(9.96), 96(9.9), 97(9.93), 98(9.92) \\
100(9.92), 101(9.93), 102(9.93), 103(9.91), 104(9.95), 105(10), 109(10), 110(10), 111(10), 112(10)\end{array}$ & 0.25 & 0.15 & 0.78 & 0.88 & - & - \\
\hline 11 & $\mathrm{~S}$ & $\begin{array}{l}52(1.5), 92(9.36), 93(9.13), 94(9.44), 95(9.39), 96(9.1), 97(9.32), 98(8.89), 100(8.89), 101(9.04), \\
102(9.19), 103(9.11), 104(9.5), 105(9.9), 109(9.99), 110(9.99), 111(10), 112(10)\end{array}$ & 0.75 & 0.65 & 0.5 & 0.36 & - & - \\
\hline 12 & $\mathrm{~S}$ & $\begin{array}{l}\text { 63(8.3),64(8.3),65(8.3),66(8.3),72(8.3),92(9.98),93(9.98),94(9.99), } 95(9.99), 96(9.97) \\
97(9.95), 98(9.98), 100(9.98), 101(9.98), 102(9.98), 103(9.97), 104(9.96), 105(10) \\
109(10), 110(10), 111(10), 112(10)\end{array}$ & 0.25 & 0.15 & 0.8 & 0.89 & - & - \\
\hline 13 & $\mathrm{R}$ & $16(7.88), 17(7.88), 18(7.88), 19(7.88)$ & 1 & 1 & - & - & 0.88 & 0.83 \\
\hline 14 & $\mathrm{R}$ & $24(5.75), 26(5.75)$ & 1 & 1 & - & - & 0.95 & 0.92 \\
\hline 15 & $\mathrm{R}$ & $\begin{array}{l}28(7.17), 29(7.17), 30(7.17), 92(9.98), 93(9.98), 94(9.98), 95(9.98), 96(9.06), 97(9.84), 98(10), \\
99(8.13), 100(9.71), 101(10), 102(10), 103(10), 104(10)\end{array}$ & 0.25 & 0.15 & 0.78 & 0.88 & 0.22 & 0.12 \\
\hline 16 & $\mathrm{R}$ & $\begin{array}{l}\text { 13(5.75),28(5.75),92(9.99),93(9.99),94(9.99),95(9.99),96(7.1),97(9.76),98(10),99(7.17), } \\
100(9.9), 101(10), 102(10), 103(10), 104(10)\end{array}$ & 0.25 & 0.15 & 0.77 & 0.86 & 0.23 & 0.14 \\
\hline 17 & $\mathrm{R}$ & & 1 & 1 & - & - & 1 & 1 \\
\hline 18 & $\mathrm{R}$ & $17(1.5)$ & 1 & 1 & - & - & 1 & 1 \\
\hline 19 & $\mathrm{R}$ & $\begin{array}{l}13(5.75), 18(5.75), 92(9.99), 93(9.99), 94(9.99), 95(9.99), 96(6.7), 97(9.86) \\
98(10), 99(8.53), 100(9.94), 101(10), 102(10), 103(10), 104(10)\end{array}$ & 0.25 & 0.15 & 0.75 & 0.85 & 0.25 & 0.15 \\
\hline 20 & $\mathrm{R}$ & $21(1.5)$ & 1 & 1 & - & - & 1 & 1 \\
\hline 21 & $\mathrm{R}$ & $20(5.75), 22(5.75)$ & 1 & 1 & - & - & 1 & 1 \\
\hline 22 & $\mathrm{R}$ & $21(5.75), 39(5.75)$ & 1 & 1 & - & - & 1 & 1 \\
\hline 23 & $\mathrm{R}$ & $22(5.75), 27(5.75)$ & 1 & 1 & - & - & 0.94 & 0.92 \\
\hline 24 & $\mathrm{R}$ & $14(5.75), 27(5.75)$ & 1 & 1 & - & - & 0.94 & 0.92 \\
\hline 25 & $\mathrm{R}$ & $\begin{array}{l}33(5.75), 35(5.75), 92(9.91), 93(9.91), 94(9.91), 95(9.93), 96(9.92), 97(9.93), 98(10), 99(9.73) \\
100(6.1), 101(10), 102(10), 103(10), 104(10)\end{array}$ & 0.25 & 0.15 & 0.76 & 0.86 & 0.24 & 0.14 \\
\hline 26 & $\mathrm{R}$ & $\begin{array}{l}\text { 14(5.75),27(5.75),92(9.95),93(9.95),94(9.95),95(9.96),96(8.11),97(9.03), } 98(10), 99(4.14) \\
100(9.89), 101(10), 102(10), 103(10), 104(10)\end{array}$ & 0.25 & 0.15 & 0.77 & 0.86 & 0.23 & 0.14 \\
\hline 27 & $\mathrm{R}$ & $\begin{array}{l}23(7.88), 24(7.88), 26(7.88), 28(7.88), 92(9.82), 93(9.82), 94(9.82), 95(9.85) \\
96(9.59), 97(9.18), 98(10), 99(8.37), 100(9.63), 101(10), 102(10), 103(10), 104(10)\end{array}$ & 0.25 & 0.15 & 0.79 & 0.88 & 0.21 & 0.12 \\
\hline 28 & $\mathrm{R}$ & $\begin{array}{l}15(7.17), 26(7.17), 27(7.17), 92(9.98), 93(9.98), 94(9.98), 95(9.98), 96(8.28), 97(9.75), 98(10), \\
99(6.86), 100(9.83), 101(10), 102(10), 103(10), 104(10)\end{array}$ & 0.25 & 0.15 & 0.8 & 0.89 & 0.2 & 0.11 \\
\hline 29 & $\mathrm{R}$ & $\begin{array}{l}30(1.5), 92(9.97), 93(9.97), 94(9.97), 95(9.97), 96(9.47), 97(9.86), 98(10), 99(8.67), 100(9.47) \\
101(10), 102(10), 103(10), 104(10)\end{array}$ & 0.75 & 0.65 & 0.37 & 0.40 & 0.63 & 0.6 \\
\hline 30 & $\mathrm{R}$ & $\begin{array}{l}29(1.5), 92(9.98), 93(9.98), 94(9.98), 95(9.98), 96(9.76), 97(9.94), 98(10), 99(9.48), 100(9.29) \text {, } \\
101(10), 102(10), 103(10), 104(10)\end{array}$ & 0.25 & 0.15 & 0.75 & 0.85 & 0.25 & 0.15 \\
\hline 31 & $\mathrm{R}$ & $32(1.5)$ & 1 & 1 & - & 1 & 1 & \\
\hline 32 & $\mathrm{R}$ & $31(1.5)$ & 1 & 1 & - & - & 1 & 1 \\
\hline 33 & $\mathrm{R}$ & $\begin{array}{l}25(1.5), 92(9.92), 93(9.92), 94(9.92), 95(9.93), 96(9.96), 97(9.96), 98(10), 99(9.88), 100(2.33) \\
101(10), 102(10), 103(10), 104(10)\end{array}$ & 0.25 & 0.15 & 0.76 & 0.86 & 0.24 & 0.14 \\
\hline 34 & $\mathrm{R}$ & & 1 & 1 & - & - & 1 & 1 \\
\hline 35 & $\mathrm{R}$ & $25(1.5)$ & 1 & 1 & - & - & 0.96 & 0.94 \\
\hline 36 & $\mathrm{R}$ & $39(1.5)$ & 1 & 1 & - & - & 1 & 1 \\
\hline 37 & $\mathrm{R}$ & $38(5.75), 39(5.75)$ & 1 & 1 & - & - & 1 & 1 \\
\hline 38 & $\mathrm{R}$ & $37(5.75), 39(5.75)$ & 1 & 1 & - & - & 1 & 1 \\
\hline 39 & $\mathrm{R}$ & $37(5.75), 38(5.75)$ & 1 & 1 & - & - & 1 & 1 \\
\hline 40 & $\mathrm{R}$ & $\begin{array}{l}49(5.75), 65(5.75), 92(1.5), 93(1.5), 94(1.5), 95(2.71), 96(9.99), 97(9.85), 98(9.87), 99(9.97) \\
100(9.93), 101(9.8), 102(9.79), 103(10), 104(10)\end{array}$ & 0.25 & 0.15 & 0.78 & 0.88 & 0.22 & 0.12 \\
\hline 41 & $\mathrm{R}$ & & 1 & 1 & - & - & 1 & 1 \\
\hline 42 & $\mathrm{R}$ & $\begin{array}{l}92(8.45), 93(8.45), 94(8.45), 95(8.67), 96(9.95), 97(9.62), 98(9.97), 99(9.82), 100(9.68), \\
101(9.97), 102(9.97), 103(10), 104(10)\end{array}$ & 0.25 & 0.15 & 0.75 & 0.85 & 0.25 & 0.15 \\
\hline 43 & $\mathrm{R}$ & $44(5.75), 45(5.75)$ & 1 & 1 & - & - & 1 & 1 \\
\hline 44 & $\mathrm{R}$ & $43(1.5)$ & 1 & 1 & - & - & 1 & 1 \\
\hline 45 & $\mathrm{R}$ & $43(1.5)$ & 1 & 1 & - & - & 1 & 1 \\
\hline 46 & $\mathrm{R}$ & $47(5.75), 48(5.75)$ & 1 & 1 & - & - & 1 & 1 \\
\hline 47 & $\mathrm{R}$ & $46(1.5)$ & 1 & 1 & - & - & 1 & 1 \\
\hline 48 & $\mathrm{R}$ & $46(5.75), 51(5.75)$ & 1 & 1 & - & - & 1 & 1 \\
\hline
\end{tabular}


Table A1. Continued.

\begin{tabular}{|c|c|c|c|c|c|c|c|c|}
\hline Node $i$ & Node type & Predecessor node $j$ (along with value $\alpha_{i j}$ ) & $y_{i}^{A}$ & $y_{i}^{B}$ & $c_{i}^{A}$ & $c_{i}^{B}$ & $w_{i}^{A}$ & $w_{i}^{B}$ \\
\hline 49 & $\mathrm{R}$ & $\begin{array}{l}40(7.88), 53(7.88), 56(7.88), 65(7.88), 92(8.49), 93(8.49), 94(8.49), 95(8.71), \\
96(10), 97(9.98), 98(9.1), 99(10), 100(9.98), 101(9.24), 102(9.22), 103(10), 104(10)\end{array}$ & 0.25 & 0.15 & 0.81 & 0.9 & 0.19 & 0.1 \\
\hline 50 & $\mathrm{R}$ & & 1 & 1 & - & - & 1 & 1 \\
\hline 51 & $\mathrm{R}$ & $48(5.75), 52(5.75)$ & 1 & 1 & - & - & 1 & 1 \\
\hline 52 & $\mathrm{R}$ & $51(1.5)$ & 1 & 1 & - & - & 1 & 1 \\
\hline 53 & $\mathrm{R}$ & $49(7.17), 54(7.17), 56(7.17)$ & 0.25 & 0.15 & 0.8 & 0.89 & 0.2 & 0.11 \\
\hline 54 & $\mathrm{R}$ & $53(5.75), 57(5.75)$ & 0.25 & 0.15 & 0.78 & 0.87 & 0.22 & 0.13 \\
\hline 55 & $\mathrm{R}$ & $57(1.5)$ & 1 & 1 & - & - & 0.96 & 0.94 \\
\hline 56 & $\mathrm{R}$ & $\begin{array}{l}49(5.75), 53(5.75), 92(9.17), 93(9.17), 94(9.17), 95(9.29), 96(10), 97(9.99), \\
98(8.28), 99(10), 100(9.98), 101(9.6), 102(9.59), 103(10), 104(10)\end{array}$ & 0.25 & 0.15 & 0.78 & 0.88 & 0.22 & 0.12 \\
\hline 57 & $\mathrm{R}$ & $\begin{array}{l}54(5.75), 55(5.75), 92(9.22), 93(9.22), 94(9.22), 95(9.33), 96(9.99), 97(9.96), \\
98(9.93), 99(9.96), 100(9.39), 101(9.98), 102(9.98), 103(10), 104(10)\end{array}$ & 0.25 & 0.15 & 0.77 & 0.86 & 0.23 & 0.14 \\
\hline 58 & $\mathrm{R}$ & & 1 & 1 & - & - & 1 & 1 \\
\hline 59 & $\mathrm{R}$ & $\begin{array}{l}63(5.75), 82(5.75), 92(9.96), 93(9.96), 94(9.96), 95(9.97), 96(10), 97(10), 98(9.75), \\
99(10), 100(10), 101(8.94), 102(8.91), 103(9.78), 104(9.83)\end{array}$ & 0.25 & 0.15 & 0.75 & 0.85 & 0.25 & 0.15 \\
\hline 60 & $\mathrm{R}$ & $\begin{array}{l}61(1.5), 92(9.88), 93(9.88), 94(9.88), 95(9.89), 96(10), 97(10), 98(8.5) \\
99(10), 100(10), 101(8.67), 102(8.63), 103(9.96), 104(9.97)\end{array}$ & 0.75 & 0.65 & 0.37 & 0.4 & 0.63 & 0.6 \\
\hline 61 & $\mathrm{R}$ & $\begin{array}{l}60(1.5), 92(9.69), 93(9.69), 94(9.69), 95(9.74), 96(10), 97(9.99), 98(9.28), \\
99(10), 100(10), 101(5.79), 102(5.67), 103(9.97), 104(9.98)\end{array}$ & 0.25 & 0.15 & 0.75 & 0.85 & 0.25 & 0.15 \\
\hline 62 & $\mathrm{R}$ & $63(1.5)$ & 1 & 1 & - & - & 1 & 1 \\
\hline 63 & $\mathrm{R}$ & $59(7.17), 62(7.17), 72(7.17)$ & 1 & 1 & - & - & 0.89 & 0.84 \\
\hline 64 & $\mathrm{R}$ & $\begin{array}{l}65(7.17), 84(7.17), 86(7.17), 92(10), 93(10), 94(10), 95(10) \\
96(10), 97(10), 98(10), 99(10), 100(10), 101(9.99), 102(9.99), 103(5.64), 104(6.64)\end{array}$ & 0.25 & 0.15 & 0.77 & 0.87 & 0.23 & 0.13 \\
\hline 65 & $\mathrm{R}$ & $\begin{array}{l}64(1.5), 92(10), 93(10), 94(10), 95(10), 96(10), 97(10) \\
98(10), 99(10), 100(10), 101(9.99), 102(9.99), 103(5.59), 104(6.6)\end{array}$ & 0.25 & 0.15 & 0.76 & 0.86 & 0.24 & 0.14 \\
\hline 66 & $\mathrm{R}$ & $67(5.75), 85(5.75)$ & 1 & 1 & - & - & 0.95 & 0.92 \\
\hline 67 & $\mathrm{R}$ & $66(5.75), 69(5.75)$ & 1 & 1 & - & - & 1 & 1 \\
\hline 68 & $\mathrm{R}$ & & 1 & 1 & - & - & 1 & 1 \\
\hline 69 & $\mathrm{R}$ & $67(1.5)$ & 1 & 1 & - & - & 1 & 1 \\
\hline 70 & $\mathrm{R}$ & $88(1.5)$ & 1 & 1 & - & - & 1 & 1 \\
\hline 71 & $\mathrm{R}$ & $\begin{array}{l}92(10), 93(10), 94(10), 95(10), 96(10), 97(10), 98(9.99) \\
99(10), 100(10), 101(9.97), 102(9.97), 103(1.5), 104(3.45)\end{array}$ & 0.25 & 0.15 & 0.75 & 0.85 & 0.25 & 0.15 \\
\hline 72 & $\mathrm{R}$ & $\begin{array}{l}73(1.5), 92(10), 93(10), 94(10), 95(10), 96(10), 97(10) \\
98(9.99), 99(10), 100(10), 101(9.95), 102(9.95), 103(4.77), 104(5.97)\end{array}$ & 0.25 & 0.15 & 0.75 & 0.85 & 0.25 & 0.15 \\
\hline 73 & $\mathrm{R}$ & $72(1.5)$ & 1 & 1 & - & - & 0.96 & 0.94 \\
\hline 74 & $\mathrm{R}$ & $76(1.5)$ & 1 & 1 & - & - & 0.96 & 0.94 \\
\hline 75 & $\mathrm{R}$ & & 1 & 1 & - & - & 1 & 1 \\
\hline 76 & $\mathrm{R}$ & $\begin{array}{l}74(1.5), 92(10), 93(10), 94(10), 95(10), 96(10), 97(10) \\
98(9.97), 99(10), 100(10), 101(9.89), 102(9.89), 103(8.2), 104(8.61)\end{array}$ & 0.25 & 0.15 & 0.75 & 0.85 & 0.25 & 0.15 \\
\hline 77 & $\mathrm{R}$ & $92(9.99), 93(9.99), 94(9.99), 95(10), 96(10), 97(10), 98(9.9), 99(10)$ & 0.25 & 0.15 & 0.75 & 0.85 & 0.25 & 0.15 \\
\hline 78 & $\mathrm{R}$ & $\begin{array}{l}89(5.75), 91(5.75) \\
100(10), 101(9.87), 102(9.86), 103(9.57), 104(9.67)\end{array}$ & 1 & 1 & - & - & 1 & 1 \\
\hline 79 & $\mathrm{R}$ & $80(1.5)$ & 1 & 1 & - & - & 0.96 & 0.94 \\
\hline 80 & $\mathrm{R}$ & $\begin{array}{l}79(5.75), 81(5.75), 92(9.98), 93(9.98), 94(9.98), 95(9.98), 96(10), 97(10), 98(9.4), \\
99(10), 100(10), 101(9.75), 102(9.74), 103(9.93), 104(9.94)\end{array}$ & 0.25 & 0.15 & 0.75 & 0.85 & 0.25 & 0.15 \\
\hline 81 & $\mathrm{R}$ & $80(5.75), 82(5.75)$ & 1 & 1 & - & - & 0.95 & 0.92 \\
\hline 82 & $\mathrm{R}$ & $81(5.75), 91(5.75)$ & 1 & 1 & - & - & 1 & 1 \\
\hline 83 & $\mathrm{R}$ & $85(1.5)$ & 1 & 1 & - & - & 0.96 & 0.94 \\
\hline 84 & $\mathrm{R}$ & $64(7.88), 85(7.88), 86(7.88), 87(7.88)$ & 1 & 1 & - & - & 0.87 & 0.82 \\
\hline 85 & $\mathrm{R}$ & $\begin{array}{l}64(7.17), 84(7.17), 86(7.17), 92(10), 93(10), 94(10), 95(10), 96(10), \\
97(10), 98(10), 99(10), 100(10), 101(10), 102(9.99), 103(9.16), 104(9.35)\end{array}$ & 0.25 & 0.15 & 0.77 & 0.87 & 0.23 & 0.13 \\
\hline 86 & $\mathrm{R}$ & $64(7.17), 84(7.17), 85(7.17)$ & 1 & 1 & - & - & 0.88 & 0.83 \\
\hline 87 & $\mathrm{R}$ & & 1 & 1 & - & - & 1 & 1 \\
\hline 88 & $\mathrm{R}$ & & 1 & 1 & - & - & 1 & 1 \\
\hline 89 & $\mathrm{R}$ & $78(1.5)$ & 1 & 1 & - & - & 1 & 1 \\
\hline 90 & $\mathrm{R}$ & & 1 & 1 & - & - & 1 & 1 \\
\hline 91 & $\mathrm{R}$ & $78(1.5)$ & 1 & 1 & - & - & 1 & 1 \\
\hline 92 & $\mathrm{H}$ & $13(5.75), 18(5.75)$ & 1 & 1 & - & - & 1 & 1 \\
\hline 93 & $\mathrm{H}$ & $23(1.5)$ & 1 & 1 & - & - & 1 & 1 \\
\hline 94 & $\mathrm{H}$ & $16(5.75), 28(5.75)$ & 1 & 1 & - & - & 0.88 & 0.84 \\
\hline 95 & $\mathrm{H}$ & $33(1.5)$ & 1 & 1 & - & - & 0.96 & 0.94 \\
\hline 96 & $\mathrm{H}$ & $59(7.17), 61(7.17), 62(7.17)$ & 1 & 1 & - & - & 0.89 & 0.84 \\
\hline 97 & $\mathrm{H}$ & $63(8.3), 64(8.3), 65(8.3), 66(8.3), 72(8.3)$ & 1 & 1 & - & - & 0.81 & 0.74 \\
\hline 98 & $\mathrm{H}$ & $40(7.88), 42(7.88), 53(7.88), 54(7.88)$ & 1 & 1 & - & - & 0.75 & 0.67 \\
\hline 99 & $\mathrm{H}$ & $40(7.88), 42(7.88), 53(7.88), 54(7.88)$ & 1 & 1 & - & - & 0.75 & 0.67 \\
\hline 100 & $\mathrm{H}$ & $40(7.88), 42(7.88), 53(7.88), 54(7.88)$ & 1 & 1 & - & - & 0.75 & 0.67 \\
\hline 101 & $\mathrm{H}$ & $40(7.88), 42(7.88), 53(7.88), 54(7.88)$ & 1 & 1 & - & - & 0.75 & 0.67 \\
\hline 102 & $\mathrm{H}$ & $49(5.75), 53(5.75)$ & 1 & 1 & - & - & 0.87 & 0.84 \\
\hline 103 & $\mathrm{H}$ & $59(7.17), 61(7.17), 62(7.17)$ & 1 & 1 & - & - & 0.89 & 0.84 \\
\hline 104 & $\mathrm{H}$ & $63(8.3), 64(8.3), 65(8.3), 66(8.3), 72(8.3)$ & 1 & 1 & - & - & 0.81 & 0.74 \\
\hline 105 & $\mathrm{H}$ & $27(1.5)$ & 1 & 1 & - & - & 0.96 & 0.93 \\
\hline 106 & $\mathrm{H}$ & $40(7.88), 42(7.88), 53(7.88), 54(7.88)$ & 1 & 1 & - & - & 0.75 & 0.67 \\
\hline 107 & $\mathrm{H}$ & $33(1.5)$ & 1 & 1 & - & - & 0.96 & 0.94 \\
\hline 108 & $\mathrm{H}$ & & 1 & 1 & - & - & 1 & 1 \\
\hline 109 & $\mathrm{H}$ & $25(1.5)$ & 1 & 1 & - & - & 0.96 & 0.94 \\
\hline 110 & $\mathrm{H}$ & & 1 & 1 & - & - & 1 & 1 \\
\hline 111 & $\mathrm{H}$ & & 1 & 1 & - & - & 1 & 1 \\
\hline 112 & $\mathrm{H}$ & & 1 & 1 & - & - & 1 & 1 \\
\hline
\end{tabular}


Acknowledgements. This work has been partially funded by European Union, by Regione Liguria, and by Provincia della Spezia under the Interreg III B Program - Alpine Space CatchRisk Project.

Edited by: T. Glade

Reviewed by: S. Fuchs and K. Hollenstein

\section{References}

Balducelli, C. and D'Esposito, C.: Genetic agents in an EDSS system to optimize resources management and risk object evacuation, Safety Science, 35, 59-73, 2000.

Bogardi, J. J.: Hazards, risks and vulnerabilities in a changing environment: the unexpected onslaught on human security?, Global Environmental Change, 14, 361-365, 2004.

Cutter, S. L.: Vulnerability to environmental hazards, Progress in Human Geography, 20, 529-539, 1996.

Fabiano, B., Currò, F., Palazzi, E., and Pastorino, R.: A framework for risk assessment and decision-making strategies in dangerous good transportation, J. Hazard. Mater., 93, 1-15, 2002.

Fiorucci, P., Gaetani, F., Minciardi, R., and Trasforini, E.: Natural risk assessment and decision planning for disaster mitigation, Advances in Geosciences, 2, 161-165, 2005,

\section{SRef-ID: 1680-7359/adgeo/2005-2-161.}

Giglio, D., Minciardi, R., Pizzorni, D., Rudari, R., Sacile, R., Tomasoni, A., and Trasforini, E.: A decision support system for real time risk assessment of hazardous material transport on road, Transactions of the 2nd Biennial Meeting of the International Environmental Modelling and Software Society iEMSs 2004, Osnabreuck, 14-17 June 2004, Manno, Switzerland, 2004.
Howard, R. A. and Matheson, J. E.: The principles and applications of decision analysis, Strategic Decisions Group, Palo Alto, CA, 1984.

Horritt, M. S. and Bates, P. D.: Evaluation of 1D and 2D numerical models for predicting river inundation, J. Hydrol., 268, 87-99, 2002.

Kottegoda, N. T. and Rosso, R.: Statistic, probability, and reliability for civil and environmental engineers, The McGraw-Hill Companies, Inc., Singapore, 1997.

Krzysztofowicz, R.: The case for probabilistic forecasting in hydrology, J. Hydrol., 249, 2-9, 2001.

Lavell, A.: An Approach to Concept and Definition in Risk management Terminology and Practice, October 2000, Northumbria University, Internal Report available at http://online. northumbria.ac.uk/, 2000.

Minciardi, R., Sacile, R., Taramasso, A. C., Trasforini, E., and Traverso, S.: Modeling the vulnerability of complex territorial systems: An application to hydrological risk, Environmental Modelling and Software, in press, 2005.

Schachter, R.: Probabilistic Inference and Influence Diagrams, Operations Research, 36, 589-604, 1988.

Shenoy, P.: Valuation-Based systems for Bayesian Decision Analysis, Operations Research, 40, 463-484, 1992.

Siccardi, F., Boni, G., Ferraris, L., and Rudari, R.: A hydrometeorological approach for Probabilistic Flood Forecast, J. Geophys. Res., 110, D05101, doi:10.1029/2004JD005314, 2005.

Varnes, D.: Landslide hazard zonation: a review of principles and practice, Paris, UNESCO, 1984.

Wybo, J. L., Guarniéri, F., and Richard, B.: Forest fire danger assessment methods and decision support, Safety Science, 20, 6170,1995 . 